\title{
Overexpression of Galectin-3 in Chronic Lymphocytic Leukemia Is Associated With 17p Deletion: A Short Report
}

\author{
ZUZANA MICHALOVÁ ${ }^{1,2 *}$, MATÚŠ ČOMA ${ }^{2,3}$, MIROSLAVA KIČOVÁ ${ }^{1,2}$, JULIANA GABZDILOVÁ $^{4}$, \\ KINGA DEDINSKÁ ${ }^{4}$, TOMÁS̆ GUMAN ${ }^{4}$, MARTINA HÁJIKOVÁ ${ }^{1,2}$, \\ DOMINIKA VESELINYOVÁ ${ }^{5}$, MÁRIA GIERTLOVA ${ }^{5}$, PETER GÁL ${ }^{3,6,7}$ and MAREK ŠARIŠSKÝ ${ }^{1,2 *}$ \\ ${ }^{1}$ Central Laboratory of Clinical Cytometry, Department of Pharmacology, \\ Faculty of Medicine, P.J. Safarik University \& Medirex, a.s., Kosice, Slovak Republic; \\ ${ }^{2}$ Department of Pharmacology, Faculty of Medicine, P.J. Safarik University, Kosice, Slovak Republic; \\ ${ }^{3}$ Department of Biomedical Research, East-Slovak Institute of Cardiovascular Diseases, Inc., Kosice, Slovak Republic; \\ ${ }^{4}$ Department of Hematology and Oncohematology, Louis Pasteur University \\ Hospital and Faculty of Medicine, P.J. Safarik University, Kosice, Slovak Republic; \\ ${ }^{5}$ Department of Clinical Genetics, Medirex a.s., Kosice, Slovak Republic; \\ ${ }^{6}$ Prague Burn Centre, Third Faculty of Medicine, Charles University, Prague, Czech Republic; \\ ${ }^{7}$ Laboratory of Cell Interactions, MediPark, P.J. Safarik University, Kosice, Slovak Republic
}

\begin{abstract}
Background/Aim: Galectins belong to the family of galactose-binding proteins known to play an important role in the processes of cell proliferation, differentiation, migration and neoplastic progression. Herein, we studied the expression of galectin-3 (Gal-3) in chronic lymphocytic leukemia (CLL). Materials and Methods: The expression of Gal-3 was analyzed by means of multiparametric flow cytometry in normal and pathological B-cells from peripheral blood and bone marrow samples of 67 patients with CLL. Results: Pathological B-cells expressed significantly higher levels of cytoplasmic Gal-3 than normal $B$-cells. Moreover, overexpression of cytoplasmic Gal-3 was observed in the prognostically poorest subgroup of CLL patients, namely those with 17p deletion. Conclusion: Our results indicate a possible role of galectin-3 in CLL pathophysiology and its potential value as a prognostic marker and therapeutic target.
\end{abstract}

*These Authors contributed equally to this study.

Correspondence to: Dr. Marek Sarissky, Department of Pharmacology, Faculty of Medicine, P.J. Safarik University, Trieda SNP 1, 04011 Kosice, Slovak Republic. Tel: +421 556404385, e-mail: marek.sarissky@upjs.sk or Dr. Peter Gál, East-Slovak Institute of Cardiovascular Diseases, Inc., Department of Biomedical Research, Ondavská 8, 04011 Košice, Slovak Republic. Tel: +421 556404277, Fax: +421 557891610, e-mail: galovci@yahoo.com or pgal@vusch.sk

Key Words: Galectin-3, chronic lymphocytic leukemia, B-cells, flow cytometry, cytogenetics, $17 \mathrm{p}$ deletion.
In hematological malignancies, galectins are involved in the regulation of numerous (patho)physiological events including cell proliferation, apoptosis, angiogenesis, inflammatory responses, drug resistance, and tumor progression [reviewed in (1-3)]. The chimera-type lectin, galectin-3 (Gal-3), a 35-kDa protein coded by LGALS3 gene located on chromosome 14 (4), is widely expressed in humans, including all types of immune cell (macrophages, monocytes, dendritic cells, eosinophils, mast cells, natural killer cells, and activated T- and Bcells), epithelial cells, endothelial cells and sensory neurons [reviewed in (5)]. In patients with chronic B-cellderived neoplasms, high levels of Gal-3 protein were found in those with diffuse large B-cell lymphoma, primary effusion lymphoma, and multiple myeloma, but it was not detected in Burkitt lymphoma, follicular lymphoma, marginal zone lymphoma, mucosa-associated lymphoid tissue lymphoma or small lymphocytic lymphoma (6). In a single existing study of Gal-3 in chronic lymphocytic leukemia (CLL) (7), down-regulation of LGALS3 mRNA was observed in patients with CLL compared with healthy individuals. Higher representation of $L G A L S 3$ mRNA was observed in patients with indolent disease compared with the group with progressive disease.

In the present study, we analyzed the expression of Gal-3 in patients with CLL by flow cytometry and, to our knowledge, for the first time studied possible relationships between its expression and prognostically significant chromosomal abnormalities, including deletions of $11 \mathrm{q}, 13 \mathrm{q}$ and $17 \mathrm{p}$, and trisomy 12 . 


\section{Materials and Methods}

Samples. Peripheral blood (PB) and bone marrow (BM) samples from 67 patients with CLL (for details see Table I) were collected after obtaining written informed consent. The samples were processed and analyzed within $24 \mathrm{~h}$ of collection. The diagnosis of CLL was established using the International Workshop CLL guidelines (8).

Flow cytometry. In order to establish the immunophenotypic diagnosis of CLL, multiparametric flow cytometric analysis was routinely performed for each patient with suspicion of chronic B-cell lymphoproliferative disorder using standard 8-color staining with a panel of antibodies targeted against the following antigens: cluster of differentiation (CD) 3, CD4, CD5, CD8, CD10, CD11c, CD19, CD20, CD22, CD23, CD27, CD34, CD38, CD43, CD45, CD56, CD79b, CD81, CD103, CD200, Flinders Medical Centre 7 (FMC7, epitope on CD20), leukocyte-associated immunoglobulin-like receptor 1 (LAIR1), mIgM, mIgKappa and mIgLambda. In patients with an established diagnosis of CLL based on International Workshop CLL criteria including immunophenotype, the expression of Gal-3 both on the cell surface (mGal-3) and intracellularly (cyGal-3) was analyzed using a phycoerythrin-conjugated monoclonal antibody to human Gal-3 (clone Gal397; Biolegend, San Diego, CA, USA) (9-11). For cell surface staining, all samples were processed using a standard stain-lyze-wash technique. For intracellular staining, FIX\&PERM Cell Fixation \& Permeabilization Kit (Invitrogen, Carlsbad, CA, USA) was used. After staining, samples were acquired in a Navios EX flow cytometer (Beckman Coulter, Brea, CA, USA). EuroFlow Standard Operating Protocols were used for instrument setup, fluorescence compensation and monitoring of instrument performance (12). The data were analyzed using the Infinicyt v.1.7 software package (Cytognos, Salamanca, Spain). For each sample, the following information was reported separately for normal and pathological B-cells: i) The presence or absence of the analyzed antigen (mGal-3, cyGal-3); ii) the intensity of antigen expression as reflected by the mean fluorescence intensity (MFI) expressed as relative linear arbitrary fluorescence channel units scaled from 0 to $1 \times 10^{6}$ of the stained cells after subtracting the MFI obtained for control unstained cells from the same sample. Normal mature B-cells were identified as polyclonal CD5 ${ }^{\text {neg/CD20high }} \mathrm{CD} 19^{+}$cells whereas pathological B-cells were identified as $\mathrm{CD} 5{ }^{\text {pos }} / \mathrm{CD} 20^{\text {low }} \mathrm{CD} 19^{+}$cells with monotypic expression of cell surface immunoglobulin light chains.

Interphase fluorescence in situ hybridization (iFISH). Single-cell suspensions of mononuclear cells were obtained from EDTAanticoagulated PB or BM samples by Ficoll-Urographin (Sigma, Schering; Darmstadt, Germany) density centrifugation. The iFISH studies were performed on slides bearing cells fixed in methanol/acetic $(3: 1, v / v)$ solution and stored at $-20^{\circ} \mathrm{C}$. Analysis of deletions of $11 \mathrm{q}, 17 \mathrm{p}, 13 \mathrm{q}$ and trisomy 12 was performed using XL ATM/TP53 and XL DLEU/LAMP/12cen deletion/enumeration probes (MetaSystems, Altlußheim, Germany). Denaturation and hybridization steps were performed using a ThermoBRITE hybridizer (Vysis-Abbott, Des Plaines, IL, USA). The slides were counterstained with 4',6-diamidino-2-phenylindole and the number of hybridization spots and their distribution in the nuclei were evaluated using a BX60 fluorescence microscope (Olympus, Tokyo, Japan). For each slide, the number of hybridization spots per nucleus was counted in at least 200 nuclei; only spots with a similar size, intensity, and shape were counted. For both FISH probes used,
Table I. Clinicobiological characteristics of patients with chronic lymphocytic leukemia $(C L L)(n=67)$.

\begin{tabular}{|c|c|c|}
\hline Characteristic & & Value \\
\hline Age, years & Median (range) & $67(30-87)$ \\
\hline \multirow[t]{2}{*}{ Gender, n (\%) } & Male & $41(61 \%)$ \\
\hline & Female & $26(39 \%)$ \\
\hline \multirow[t]{2}{*}{ Sample type, n (\%) } & $\mathrm{PB}$ & $50(75 \%)$ \\
\hline & $\mathrm{BM}$ & $17(25 \%)$ \\
\hline \multirow[t]{2}{*}{ Disease status, n (\%) } & Newly diagnosed & $27(40 \%)$ \\
\hline & Relapsed & $40(60 \%)$ \\
\hline WBC, $10^{9} / 1$ & Median (range) $(n=64)$ & $14.77(4-290)$ \\
\hline ALC, $10^{9} / 1$ & Median (range) $(n=51)$ & $7.74(1-279)$ \\
\hline ANC, $10^{9} / 1$ & Median (range) $(n=51)$ & $3.6(1-78)$ \\
\hline PLT, $10^{12 / 1}$ & Median (range) $(n=63)$ & $201(5-398)$ \\
\hline $\mathrm{Hb}, \mathrm{g} / \mathrm{dl}$ & Median (range) $(n=63)$ & $14(8-17)$ \\
\hline $\mathrm{B} 2 \mathrm{MG}, \mathrm{mg} / \mathrm{l}$ & Median (range) $(n=49)$ & $2.6(1-15)$ \\
\hline $\mathrm{LDH}, \mu \mathrm{kat} / \mathrm{l}$ & Median (range) $(n=56)$ & $3.79(2-12)$ \\
\hline \multirow[t]{5}{*}{ Cytogenetics, n (\%) } & Normal & $14(21 \%)$ \\
\hline & 11q deletion & $7(10 \%)$ \\
\hline & 13q deletion & $33(49 \%)$ \\
\hline & $17 \mathrm{p}$ deletion & $5(7 \%)$ \\
\hline & Trisomy 12 & $4(6 \%)$ \\
\hline \multirow[t]{2}{*}{$I G H V$ mutational status, $\mathrm{n}(\%)$} & Mutated & $19(28 \%)$ \\
\hline & Unmutated & $48(72 \%)$ \\
\hline
\end{tabular}

ALC: Absolute lymphocyte count; ANC: absolute neutrophil count; B2MG: beta-2-microglobulin; Hb: hemoglobin; IGHV: immunoglobulin heavy-chain variable region gene; LDH: lactate dehydrogenase; PLT: platelet count; WBC: white blood cell count.

a $6 \%$ cut-off level was established. Frequencies of positive nuclei in individual slides ranged from $7-95 \%$ for $13 q$ deletion, $9-72 \%$ for trisomy $12,17-67 \%$ for $11 q$ deletion and $30-97 \%$ for $17 p$ deletion.

Statistical analysis. In order to establish the statistical significance of differences observed between groups, the non-parametric MannWhitney $U$-test was used. For paired samples comparison, the Wilcoxon signed-rank test was employed. For correlation analysis, the Spearman's rho coefficient was calculated. Statistical significance was considered to be present once $p$-values were lower than 0.05 . The data from the fluorescence intensity measurements are expressed as the mean \pm standard deviation.

\section{Results}

The expression of Gal-3 was analyzed in pathological and normal B-cells both on their cell surface (mGal-3) and intracellularly (cyGal-3). B-Cells represented $47 \pm 26 \%$ of total cellularity in samples. Normal B-cells were detected in 50 out of 67 patients with CLL and represented $7 \pm 15 \%$ of all B-cells. mGal-3 consistently tested negative, whereas cyGal-3 was found in all major leukocyte populations, including lymphocytes, monocytes and neutrophils (Figure 1). The strongest cyGal-3 expression was detected in monocytes. Lymphocytes, including B-cells, showed weaker cyGal-3 expression than monocytes and 

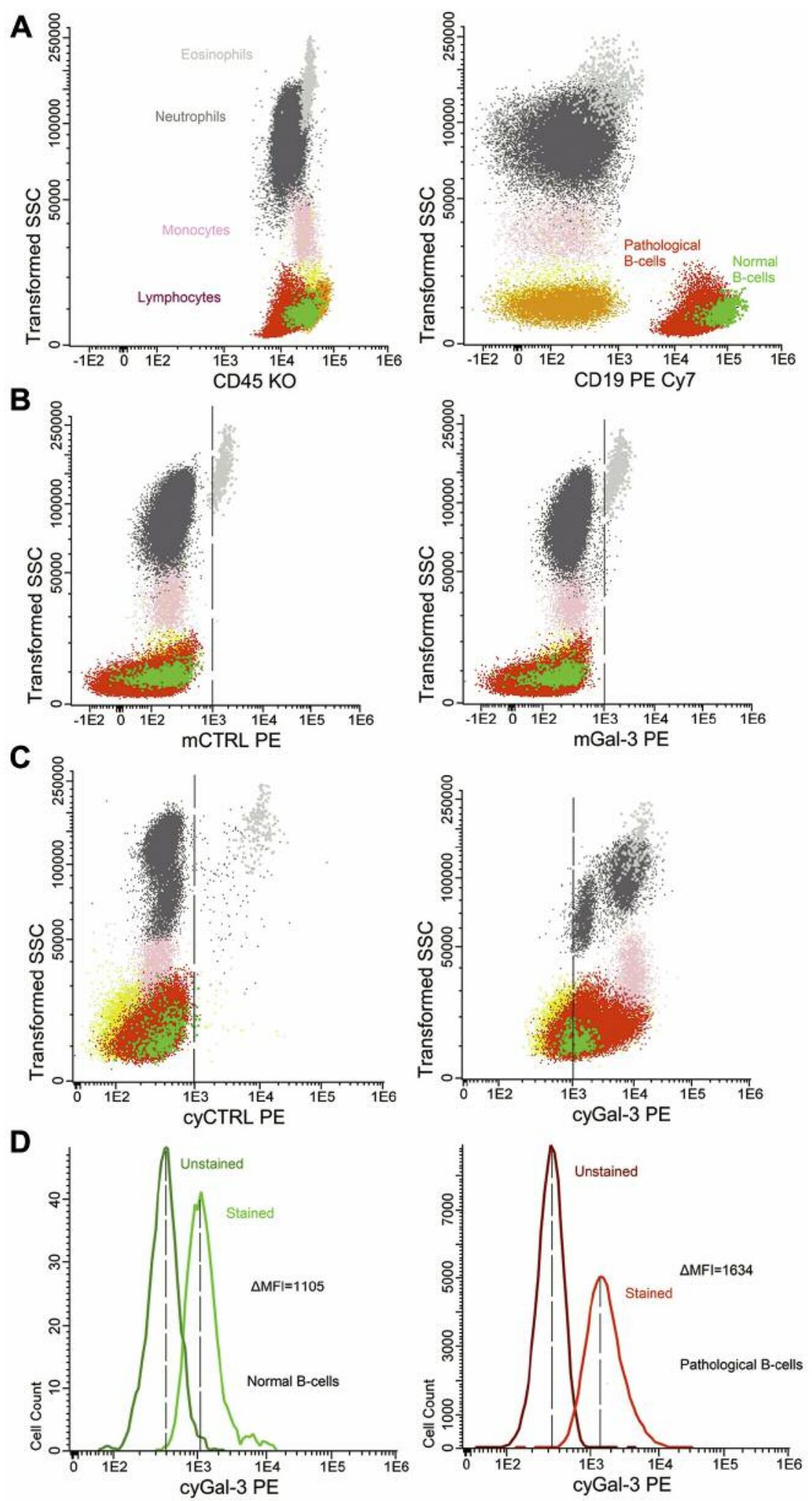

Figure 1. Illustrative bivariate dot plots and histograms showing the gating strategy to identify normal (green) and pathological (red) B-cells (A), negative expression of membranous galectin-3 $(\mathrm{mGal}-3)(B)$, positive expression of cytoplasmic $(\mathrm{cy}) \mathrm{Gal}-3(\mathrm{C})$, and increased cyGal-3 expression in pathological (right) versus normal (left) B-cells (D). CTRL: Control; CD: cluster of differentiation; KO: krome orange; PE: phycoerythrin; MFI: mean fluorescence intensity. 

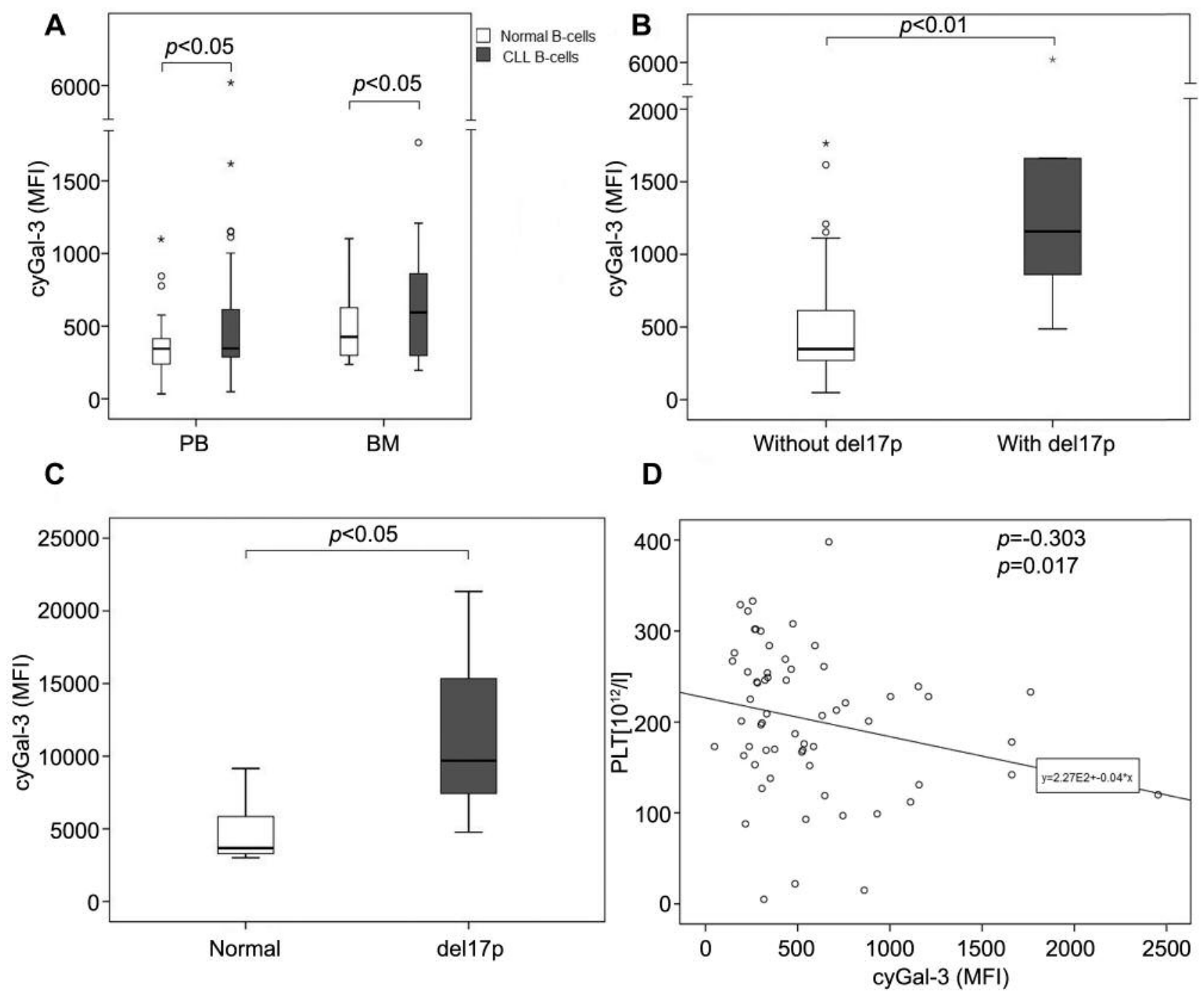

Figure 2. Graphs showing the expression of cytoplasmic (cy)Gal-3 in normal and pathological B-cells in peripheral blood (PB) and bone marrow $(B M)$ samples $(A)$, in patients with chronic lymphocytic leukemia (CLL) with and without 17p deletion (fresh samples) (B), patients with CLL with normal cytogenetics and those harboring $17 p$ deletion (frozen samples) (C), and the correlation between the expression of cyGal-3 and platelet count (D). The box plots represent the median mean fluorescence intensity (MFI) \pm standard deviation.

neutrophils. For both normal and pathological B-cells, the expression of cyGal-3 did not significantly differ between $\mathrm{PB}$ and $\mathrm{BM}$ samples (Figure 2A). However, when compared to normal B-cells, pathological B-cells showed significantly increased cyGal-3 expression in both PB and BM (369 $\pm 214 v s .628 \pm 898$, respectively, $p=0.012 ; 506 \pm 274$ vs. 664 \pm 419 , respectively, $p=0.022$ ) (Figures 1D and 2A). Moreover, when we analyzed cyGal-3 expression in relation to the cytogenetic profile of patients with CLL, cyGal-3 was found to be significantly overexpressed in those harboring $17 \mathrm{p}$ deletion compared to patients without $17 p$ deletion $(2,043 \pm 2,281 v s .498 \pm 353, p<0.01)$ (Figure 2B). To confirm this finding, we analyzed an additional 14 archival samples of cryopreserved isolated lymphocytes from patients with CLL with $17 \mathrm{p}$ deletion $(\mathrm{n}=7)$ and patients with normal iFISH findings $(n=7)$. In these cryopreserved samples, we again observed significant cyGal-3 overexpression in patients with $17 \mathrm{p}$ deletion $(11,620 \pm 6,170$ vs. $4,881 \pm 2,521$, respectively, $p=0.011)$ (Figure 2C). No associations were found between cyGal-3 expression and other examined chromosomal abnormalities (i.e. deletions of 11q, 13q, and trisomy 12). Deletion of $17 \mathrm{p}$ was associated with lower platelet count $(78 \pm 68 \mathrm{vs}$. $\left.215 \pm 66 \times 10^{12} / 1, p=0.001\right)$ and hemoglobin level $(10.2 \pm 1.5$ vs. $14.0 \pm 1.8 \mathrm{~g} / \mathrm{dl}, p=0.001)$. Similarly, the expression of cyGal-3 was correlated with a lower platelet count 
$(p=0.017)$ (Figure 2D). Of note, no further correlations were observed between the expression of cyGal-3 and the remaining clinicobiological characteristics.

\section{Discussion}

In the present work, we demonstrate, for the first time, by flow cytometric immunophenotyping that CLL B-cells display overexpression of intracellular Gal-3, which was further increased in the prognostically poorest subgroup of patients, those harboring $17 \mathrm{p}$ deletion, the most important independent prognostic factor in $\operatorname{CLL}(8,13)$. In contrast to our findings, a previous study showed decreased Gal-3 expression using both the semi-quantitative reverse transcription polymerase chain reaction (RT-PCR) at the mRNA level and flow cytometry at the protein level (7). They analyzed samples from 85 patients with CLL by RT-PCR, but only eight by flow cytometry. Apart from a lower number of patients analyzed by flow cytometry, they employed an indirect immunofluorescence method using a polyclonal antibody, whereas we used a monoclonal antibody (cell surface and intracellular flow cytometry quality control tested) and direct immunofluorescence method. Furthermore, we used residual normal polyclonal B-cells present in patient samples as internal controls instead of samples obtained from healthy donors. Out of 67 analyzed patient samples, 50 showed the presence of normal B-cells alongside CLL Bcells. Thirty-five of them showed cyGal-3 overexpression in CLL B-cells, whereas 14 showed little change or slightly decreased expression.

Among chronic B-cell lymphoproliferative disorders, overexpression of Gal-3 was also found in follicular lymphoma $(11,14)$, primary effusion lymphoma (6), intravascular large B-cell lymphoma (15) and diffuse large B-cell lymphoma $(6,11,14,16,17)$.

Several molecular mechanisms may be involved in the upregulation of Gal-3 in patients with CLL with $17 \mathrm{p}$ deletion observed in our study. For example, Gal-3 has been shown to support cell survival by diverse mechanisms. Gal-3 contains the NWGR amino acid motif found in the BH1 domain of BCL2 family proteins and supports mitochondrial stabilization by binding to BCL2 (18). Furthermore, suppression of LGALS3 by p53 is critical for p53-mediated apoptosis, suggesting that Gal-3 and p53 regulate a survival axis supporting cellular homeostasis $(3,5,19)$. Thus, a disturbed or lost p53 function, either through $17 \mathrm{p}$ deletion or p53 gene mutation, may lead to Gal-3 overexpression, with subsequent inhibition of apoptosis resulting in reduced efficiency of anticancer therapy.

To conclude, in the present work we found that pathological B-cells from patients with CLL exhibit increased expression of Gal-3 in comparison with normal B-cells. Moreover, our data suggest that the highest expression of Gal-3 is associated with 17p deletion. Therefore, therapeutic strategies targeting Gal-3 (20) may be clinically relevant, especially in this prognostically poorest subgroup of patients with CLL.

\section{Conflicts of Interest}

The Authors have no conflicts of interest to declare.

\section{Authors' Contributions}

ZM and MS conceived, planned and carried out experiments; ZM, MS and PG wrote the article; MG, DV, TG, KD and JG contributed to the acquisition of clinical data; $\mathrm{MC}, \mathrm{MK}$ and $\mathrm{MH}$ contributed to sample preparation and the interpretation of results. All Authors provided critical feedback and helped shape the research, analysis and article preparation.

\section{Acknowledgements}

This work was supported in part by the Grant Agency of the Ministry of Education, Science, Research and Sport of the Slovak Republic (No. VEGA-1/0673/19), the Agency for Science and Research (No. APVV-14-0731) and the Charles University, Prague, Czech Republic (PROGRES Q37).

\section{References}

1 Pena C, Mirandola L, Figueroa JA, Hosiriluck N, Suvorava N, Trotter K, Reidy A, Rakhshanda R, Payne D, Jenkins M, Grizzi F, Littlefield L, Chiriva-Internati $\mathrm{M}$ and Cobos E: Galectins as therapeutic targets for hematological malignancies: a hopeful sweetness. Ann Transl Med 2(9): 87, 2014. PMID: 25405162. DOI: $10.3978 /$ j.issn.2305-5839.2014.09.14

2 Kaltner H, Toegel S, Caballero GG, Manning JC, Ledeen RW and Gabius HJ: Galectins: their network and roles in immunity/tumor growth control. Histochem Cell Biol 147(2): 239-256, 2017. PMID: 28012132. DOI: $10.1007 / \mathrm{s} 00418-016-1522-8$

3 Giordano M, Croci DO and Rabinovich GA: Galectins in hematological malignancies. Curr Opin Hematol 20(4): 327-335, 2013. PMID: 23695449. DOI: 10.1097/MOH.0b013e328362370f

4 Raimond J, Zimonjic DB, Mignon C, Mattei M, Popescu NC, Monsigny $\mathrm{M}$ and Legrand A: Mapping of the galectin-3 gene ( $L G A L S 3$ ) to human chromosome 14 at region 14q21-22. Mamm Genome 8(9): 706-707, 1997. PMID: 9271684. DOI: $10.1007 /$ S003359900548

5 Newlaczyl AU and Yu LG: Galectin-3 - A jack-of-all-trades in cancer. Cancer Lett 313(2): 123-128, 2011. PMID: 21974805. DOI: $10.1016 /$ j.canlet.2011.09.003

6 Hoyer KK, Pang M, Gui D, Shintaku IP, Kuwabara I, Liu FT, Said JW, Baum LG and Teitell MA: An anti-apoptotic role for galectin3 in diffuse large B-cell lymphomas. Am J Pathol 164(3): 893-902, 2004. PMID: 14982843. DOI: 10.1016/S0002-9440(10)63177-X

7 Asgarian-Omran H, Forghani P, Hojjat-Farsangi M, Roohi A, Sharifian RA, Razavi SM, Jeddi-Tehrani M, Rabbani H and Shokri F: Expression profile of galectin-1 and galectin-3 molecules in different subtypes of chronic lymphocytic leukemia. Cancer Invest 28(7): 717-725, 2010. PMID: 20590446. DOI: $10.3109 / 07357907.2010 .494319$ 
8 Hallek M, Cheson BD, Catovsky D, Caligaris-Cappio F, Dighiero G, Döhner H, Hillmen P, Keating MJ, Montserrat E, Rai KR, Kipps TJ; International Workshop on Chronic Lymphocytic Leukemia: Guidelines for the diagnosis and treatment of chronic lymphocytic leukemia: A report from the International Workshop on Chronic Lymphocytic Leukemia updating the National Cancer Institute-Working Group 1996 guidelines. Blood 111(12): 5446-5456, 2008. PMID: 18216293. DOI: 10.1182/blood-2007-06-093906

9 Zhang X, Wan Y, Chata R, Brazzale A, Atherton JJ, Kostner K, Dimeski $G$ and Punyadeera C: A pilot study to demonstrate diagnostic potential of galectin-3 levels in saliva. J Clin Pathol 69(12): 1100-1104, 2016. PMID: 27340130. DOI: 10.1136/ jclinpath-2016-203631

10 Paz H, Joo EJ, Chou CH, Fei F, Mayo KH, Abdel-Azim H, Ghazarian H, Groffen J, Heisterkamp N. Paz H, Joo EJ, Chou $\mathrm{CH}$, Fei F, Mayo KH, Abdel-Azim H, Ghazarian H, Groffen J and Heisterkamp N: Treatment of B-cell precursor acute lymphoblastic leukemia with the galectin-1 inhibitor PTX008. J Exp Clin Cancer Resr 37(1): 67, 2018. PMID: 29580262. DOI: 10.1186/s13046-018-0721-7

11 Ramos-Medina R, Montes-Moreno S, Maestre L, Cañamero M, Rodriguez-Pinilla M, Lázaro A and Roncador G: Immunohistochemical analysis of HLDA9 Workshop antibodies against cellsurface molecules in reactive and neoplastic lymphoid tissues. Immunol Lett 134(2): 150-156, 2011. PMID: 20946916. DOI: 10.1016/j.imlet.2010.10.007

12 Kalina T, Flores-Montero J, van der Velden VH, Martin-Ayuso M, Böttcher S, Ritgen M, Almeida J, Lhermitte L, Asnafi V, Mendonça A, de Tute R, Cullen M, Sedek L, Vidriales MB, Pérez JJ, te Marvelde JG, Mejstrikova E, Hrusak O, Szczepański T, van Dongen JJ, Orfao A and EuroFlow Consortium (EU-FP6, LSHB-CT-2006018708): EuroFlow standardization of flow cytometer instrument settings and immunophenotyping protocols. Leukemia 26(9): 19862010, 2012. PMID: 22948490. DOI: 10.1038/leu.2012.122

13 Diamantopoulos PT, Samara S, Kollia P, Giannakopoulou N, Sofotasiou M, Kalala F, Kodandreopoulou E, Zervakis P, Vassilakopoulos T, Siakantaris M, Mantzourani M, Angelopoulou M, Kyrtshonis MC, Korkolopoulou P, Patsouris $\mathrm{E}$ and Viniou NA: Tumor protein 53 gene mutations without 17 p13 deletion have no significant clinical implications in chronic lymphocytic leukemia. Detection of a new mutation. Anticancer Res 37(5): 2387-2391, 2017. PMID: 28476805. DOI: 10.21873/anticanres. 11577
14 Shipp MA, Ross KN, Tamayo P, Weng AP, Kutok JL, Aguiar RC, Gaasenbeek M, Angelo M, Reich M, Pinkus GS, Ray TS, Koval MA, Last KW, Norton A, Lister TA, Mesirov J, Neuberg DS, Lander ES, Aster JC and Golub TR: Diffuse large B-cell lymphoma outcome prediction by gene-expression profiling and supervised machine learning. Nat Med 8(1): 68-74, 2002. PMID: 11786909. DOI: $10.1038 / \mathrm{nm0102-68}$

15 Mansueto G, Di Vito A, Belluomo C, Murino P, Natella V, Camastra C, Presta I, Malara N, de Rosa G, Donato G and Mignogna C: A case of intravascular large B-cell lymphoma: New clinical and immunohistochemical findings. Neuropathology 36(5): 496-503, 2016. PMID: 27090763. DOI: 10.1111/neup.12300

16 Clark MC, Pang M, Hsu DK, Liu FT, de Vos S, Gascoyne RD, Said J and Baum LG: Galectin-3 binds to CD45 on diffuse large B-cell lymphoma cells to regulate susceptibility to cell death. Blood 120(23): 4635-4644, 2012. PMID: 23065155. DOI: 10.1182/blood-2012-06-438234

17 Kim SJ, Lee SJ, Sung HJ, Choi IK, Choi CW, Kim BS, Kim JS, Yu W, Hwang HS and Kim IS: Increased serum 90K and galectin-3 expression are associated with advanced stage and a worse prognosis in diffuse large B-cell lymphomas. Acta Haematol 120(4): 211-216, 2008. PMID: 19153476. DOI: 10.1159/000193223

18 Akahani S, Nangia-Makker P, Inohara H, Kim HR and Raz A: Galectin-3: a novel antiapoptotic molecule with a functional BH1 (NWGR) domain of Bcl-2 family. Cancer Res 57(23): 5272-5276, 1997. PMID: 9393748

19 Ruvolo PP: Galectin 3 as a guardian of the tumor microenvironment. Biochim Biophys Acta 1863(3): 427-437, 2016. PMID: 26264495. DOI: 10.1016/j.bbamcr.2015.08.008

20 Sherazi AA, Jariwala KA, Cybulski AN, Lewis JW, Karagiannis J, Cumming RC and Timoshenko AV: Effects of global OGlcNacylation on galectin gene-expression profiles in human cancer cell lines. Anticancer Res 38(12): 6691-6697, 2018. PMID: 30504378. DOI: 10.21873/anticanres.13037
Received May 8, 2019

Revised May 20, 2019

Accepted May 22, 2019 